\title{
The association between frontal lobe perfusion and depressive symptoms in later life
}

Robert Briggs, Daniel Carey, Paul Claffey, Triona McNicholas, Louise Newman, Hugh Nolan, Sean P. Kennelly and Rose Anne Kenny

\section{Background}

Deficits in frontal lobe perfusion have been demonstrated in latelife depression; however, studies to date have generally involved small numbers, used neuroimaging rather than bedside testing and have not controlled for important covariates.

\section{Aims}

We aimed to examine the association between depressive symptoms and frontal lobe perfusion during standing, in a large cohort of community-dwelling older people.

\section{Method}

Participants aged $\geq 50$ years underwent continuous measurement of orthostatic blood pressure by finometry, and frontal lobe perfusion by near-infrared spectroscopy. Depressive symptoms were assessed by the eight-item Centre for Epidemiological Studies Depression Scale. Real-time frontal lobe cerebral oxygenation was measured by the Portalite System, detecting changes in frontal lobe perfusion and reporting a tissue saturation index score.

\section{Results}

Almost 8\% (209 out of 2616) had clinically significant depressive symptoms. Multilevel models demonstrated a significantly lower tissue saturation index in participants with depressive symptoms at both 60 and 90 s post-stand, with coefficients of -0.43 $(95 \% \mathrm{Cl}-0.63$ to -0.22$)$ and $-0.37(95 \% \mathrm{Cl}-0.57$ to -0.16$)$, respectively. Controlling for relevant covariates did not significantly attenuate these associations. After addition of systolic blood pressure this association was no longer significant, suggesting lower blood pressure may modify this relationship.

\section{Conclusions}

This study demonstrates that lower frontal lobe perfusion, related to lower values of baseline systolic blood pressure, is associated with clinically significant depressive symptoms in a cohort of community-dwelling older people. Given the recognised longitudinal association between lower blood pressure and depression in older people, this may represent a potential therapeutic target for prevention of incident depression.

\section{Declaration of interest}

None.

\section{Keywords}

Depression; older; cerebral perfusion; frontal lobe; blood pressure.

\section{Copyright and usage}

(c) The Royal College of Psychiatrists 2019.

\section{Background}

Structural and functional changes in the frontal lobe have been implicated in late-life depression. ${ }^{1,2}$ Neuroimaging studies have demonstrated that older people with late-onset depression have higher rates of frontal lobe atrophy than controls, as well as their older counterparts with earlier-onset depression. ${ }^{3,4}$ White matter hyperintensities (WMHs), particularly those involving the frontal lobe, are closely associated with late-life depression and progression of WMHs is associated with poorer response to treatment. ${ }^{5,6}$ It is proposed that these pathological changes in frontal lobe structure disrupt neural connections along frontostriatal circuits, which are particularly important in the regulation of mood and cognition. ${ }^{1,2}$ This is supported by neuroimaging studies demonstrating loss of functional connectivity, ${ }^{7}$ and abnormal frontal lobe biochemistry, ${ }^{8}$ as well as neuropathological studies demonstrating a reduction in frontostriatal neuronal cell volume, in depressed older people. ${ }^{3,9}$ Clinically, depression in later life is associated with presentations such as executive dysfunction and apathy, which are related to frontostriatal dysfunction. ${ }^{1,2}$ Depressed older people have demonstrated poorer scores on formal frontal lobe-related cognitive tests compared with controls, ${ }^{1}$ and late-life depression is also closely associated with other clinical syndromes where frontostriatal connectivity has been implicated, including gait disorders, dementia and urinary incontinence. The frontal lobe is particularly susceptible to damage by cerebral hypoperfusion ${ }^{10}$ and conditions affecting cerebral blood flow, such as systemic hypotension and orthostatic hypotension, have been shown to increase the risk of incident depression in older people. ${ }^{11,12}$ A hypothesised mechanism for this is via reduction in blood flow to the frontal lobe resulting in frontal WMHs and altered frontal lobe function. ${ }^{1}$ Cross-sectional single-photon emission computed tomography and magnetic resonance imaging (MRI) studies have shown frontal lobe perfusion deficits in older depressed participants when compared with controls ${ }^{13,14}$ and prospectively, reduced global cerebral perfusion measured by transcranial Doppler ultrasound is a predictor of greater depressive symptomology in older people with heart failure at 1-year follow-up. ${ }^{15}$

However, studies to date examining the association between frontal lobe cerebral perfusion and depression have involved relatively small numbers and did not control for important clinical conditions such as heart disease or stroke. Studies have also utilised imaging modalities such as MRI and single-photon emission computed tomography, rather than techniques such as near-infrared spectroscopy (NIRS). NIRS provides a non-invasive index of cerebral perfusion based on the finding that light in the near-infrared spectrum penetrates the skull and allows measurement of oxyhaemoglobin and deoxyhaemoglobin concentrations in the brain. ${ }^{16}$ It is used extensively in cardiac and other surgery to measure intra-operative cerebral perfusion on a continuous basis, and is now available outside these setting as a validated, portable non-invasive bedside test. ${ }^{17}$ The aim of this study is to examine the association between clinically significant depressive symptoms and frontal lobe cerebral perfusion, measured by NIRS, in a large cohort of community-dwelling older people, embedded within the Irish Longitudinal Study on Ageing (TILDA). Furthermore, we will determine how conditions such as orthostatic hypotension $(\mathrm{OH})$ and hypotension modify this relationship. The comprehensive TILDA data-set also allows us to control for important competing covariates such as heart disease, stroke and antidepressant use. 


\section{Method}

\section{Ethics}

The study was approved by the Faculty of Health Sciences Research Ethics Committee at Trinity College Dublin (REC Ref: 1/10/List 37) and all participants gave informed written consent. All experimental procedures adhered to the Declaration of Helsinki. All assessments were carried out by trained research nurses.

\section{Study design}

This is a cross-sectional study examining the association between clinically significant depressive symptoms and frontal lobe cerebral perfusion, measured by NIRS.

This study is embedded within TILDA, a large population-based study of a nationally representative sample of community dwelling older adults aged 50 years and over, with an initial study population of over 8000 participants.

The TILDA study design has been outlined previously. ${ }^{18} \mathrm{We}$ analysed data from the third wave of TILDA collected between 2014 and 2015. Participants were included in this study if they were aged 50 years or more, and underwent a complete health assessment at wave 3 including measurement of orthostatic blood pressure, frontal lobe perfusion by NIRS and screening for depressive symptoms.

\section{Cerebral perfusion and orthostatic blood pressure}

Real-time frontal lobe cerebral oxygenation was measured by the Artinis Portalite System, a portable, continuous-wave NIRS system, that uses spatially resolved spectroscopy, reporting absolute values, developed to measure cerebral perfusion. ${ }^{19}$ The NIRS technique, first described by Jobsis, ${ }^{20}$ is based on the property of human tissue being relatively transparent to light in the near-infrared spectrum; by measuring changes in light absorption at different wavelengths, the oxygenation of tissue can be monitored continuously. ${ }^{21}$

An optical sensor is placed on the participant's forehead, on the equivalent of the FP1 position in the international 10-20 electrode system, to measure changes in frontal lobe oxyhaemoglobin and deoxyhaemoglobin continuously. Tissue saturation index (TSI) was the primary measure used in this study, and is defined as (oxyhaemoglobin)/ (oxyhaemoglobin + deoxyhaemoglobin) $\times 100$ and expressed as a percentage. ${ }^{22}$

Continuous orthostatic blood pressure was measured in parallel with this by active stand, using a Finometer Midi (Finopres Medical Systems, Netherlands) as described previously. ${ }^{23}$ Briefly, participants lay in the supine position for $10 \mathrm{~min}$ in a quiet room, before standing in a timely manner $(<5 \mathrm{~s})$, and were aided by a research nurse to mobilise as necessary. Baseline values for TSI and blood pressure were an average of the readings between 30-60 s before standing. After standing, systolic blood pressure, diastolic blood pressure, heart rate, oxyhaemoglobin, deoxyhaemoglobin and TSI were monitored for a further $180 \mathrm{~s}$. Throughout the recording, participants stood quietly.

$\mathrm{OH}$ was defined as a drop in systolic blood pressure $\geq 20 \mathrm{~mm}$ $\mathrm{Hg}$ or drop in diastolic blood pressure $\geq 10 \mathrm{~mm} \mathrm{Hg}$ at $30 \mathrm{~s} \mathrm{com-}$ pared with baseline blood pressure. ${ }^{24}$ Signal processing included a median average filter and $10 \mathrm{~s}$ moving average filter applied to both blood pressure and NIRS data. The sampling rate of the output data was $1 \mathrm{~Hz}$. TSI was recorded continuously during the active stand but as $\mathrm{OH}$ is typically measured at 30,60 and $90 \mathrm{~s}$, we focused primarily on TSI at these time points in this study.

\section{Depression}

Depressive symptoms were assessed with the eight-item Centre for Epidemiological Studies Depression Scale (CES-D-8). ${ }^{25}$ A score of $\geq 9$ was used to define those with clinically significant depressive symptoms. ${ }^{25}$ This short-form version of the longer 20 -item scale was utilised in the TILDA study to reduce the time taken to conduct participant assessments, as well as to reduce respondent burden and fatigue, and previous work has confirmed its reliability in comparison to the 20 -item CES-D in terms of internal consistency and factor structure within the TILDA cohort. ${ }^{25,26}$ This was performed generally within 1 month of measurement of cerebral perfusion and orthostatic blood pressure.

\section{Other measures}

Detailed social and biological data were also collected. Seated systemic blood pressure was measured with an OMRON digital automatic blood pressure monitor (OMRON M10 IT Upper Arm BP Monitor). Chronic disease burden was defined as the number of chronic illnesses from the following list: liver disease, kidney disease, lung disease, cancer, arthritis and diabetes. Cardiac disease was defined as self-report of angina, prior myocardial infarct or cardiac failure. Self-report was also elicited for prior stroke. Cognitive impairment was defined as a Mini-Mental State Examination score of $\leq 24$.

Medication records were examined with Anatomical Therapeutic Classification (ATC) codes (https://www.whocc.no/ atc_ddd_index/), which are assigned to the active substances contained in medicines by the World Health Organization based on the therapeutic indication for the medicine, e.g. all antidepressants are listed under the ATC code N06A. Medication records were examined specifically for antidepressant use (ATC codes N06AB (selective serotonin reuptake inhibitors), N06AX16 (venlafaxine), N06AX21 (duloxetine), N06AX11 (mirtazapine), N06AX22 (agomelatine) and N06AX12 (bupropion)), as well as antihypertensive use (ATC codes C02 (antihypertensives), C03 (diuretics), C07 (betablockers), C08 (calcium-channel blockers) and C09 (agents acting on the renin-angiotensin system)).

\section{Statistical analysis}

Data were analysed by Stata version 14 (StataCorp for Windows). Normally distributed continuous variables were described as mean and s.d. and compared by Student's $t$-test. Categorical variables were compared by the chi-squared test.

Multilevel models with TSI as the dependent variable were used to compare TSI data across specific time points after standing, i.e. 30, 60 and $90 \mathrm{~s}$, by depressive symptoms. These models assess the effect of the two-way interaction between depressive symptoms and time (depressive symptoms $\times$ time) on TSI, which accounts for the fact that TSI at $60 \mathrm{~s}$ is significantly influenced by TSI at $30 \mathrm{~s}$, and so on.

Models were adjusted for covariates, which were chosen a priori based on their hypothesised role in modifying this relationship. Two models were tested initially: the first model was unadjusted; the second model was adjusted for age, gender, height and weight, and for clinical covariates such as cardiac disease, other chronic diseases, cognitive impairment, stroke and antidepressant use.

Further post hoc analyses were undertaken by testing further models by adding $\mathrm{OH}$ and systolic blood pressure separately to assess the role blood pressure behaviour had in modifying the relationship between depression and TSI. This allows us to analyse the three-way interaction (e.g. depressive symptoms $\times$ time $\times$ systolic blood pressure), which allows us to see whether the association between the two-way interaction of depressive symptoms $\times$ time and TSI differs depending on systolic blood pressure or $\mathrm{OH}$.

To ensure findings were independent of antidepressant use, subgroups of participants taking these medications were excluded from the analysis and models were rerun to ensure that findings 
were not significantly different when these groups were omitted. A $P$ value $\leq 0.05$ was considered statistically significant.

\section{Results}

Almost 8\% (209 out of 2616) of participants had significant depressive symptoms.
Depressed participants were more likely to be female and taking antidepressant medication. Baseline characteristics by depression status are shown in Table 1.

There were no significant differences between groups in terms of prevalence of cardiac disease, blood pressure, history of stroke and current antihypertensive drug use.

Figure 1 demonstrates mean absolute TSI after standing by depressive symptoms, and Fig. 2 presents the mean TSI drop from baseline by depressive symptoms.

\begin{tabular}{|c|c|c|c|}
\hline & Not depressed $(n=2407)$ & Depressed $(n=209)$ & Statistical test \\
\hline Age, years, mean ( $95 \% \mathrm{Cl})$ & $64.5(64.2-64.8)$ & $63.5(62.4-64.6)$ & $t=1.75 ; P=0.0796 ; d=0.13$ \\
\hline Females, \% ( $n)$ & $53(1282 / 2407)$ & $62(129 / 209)$ & $\chi^{2}=5.54 ; P=0.019$ \\
\hline Systolic blood pressure, $\mathrm{mm} \mathrm{Hg}$, mean $(95 \% \mathrm{Cl})^{\mathrm{a}}$ & $141.0(140.2-141.9)$ & $140.5(140.2-141.9)$ & $t=0.33 ; P=0.7429 ; d=0.10$ \\
\hline \multicolumn{4}{|l|}{ Cardiac disease, \% $(n)^{\mathrm{b}}$} \\
\hline Myocardial infarct & $4(99 / 2407)$ & $4(9 / 209)$ & $\chi^{2}=0.02 ; P=0.893$ \\
\hline Cardiac failure & $1(12 / 2407)$ & $1(3 / 209)$ & $\chi^{2}=2.96 ; P=0.085$ \\
\hline Angina & $3(80 / 2407)$ & $6(12 / 209)$ & $\chi^{2}=3.31 ; P=0.069$ \\
\hline \multicolumn{4}{|l|}{ Chronic disease number, $\%(n)^{\mathrm{c}}$} \\
\hline 0 & $63(1515 / 2407)$ & $46(96 / 209)$ & $\chi^{2}=24.13 ; P<0.001$ \\
\hline 1 & $32(770 / 2407)$ & $45(95 / 209)$ & \\
\hline 2 & $5(114 / 2407)$ & $8(17 / 209)$ & \\
\hline 3 & $0(33 / 2407)$ & $0(1 / 209)$ & \\
\hline Prior stroke, \% $(n)^{\mathrm{d}}$ & $1(32 / 2407)$ & $1(3 / 209)$ & $\chi^{2}=0.02 ; P=0.898$ \\
\hline MMSE, mean $(95 \% \mathrm{Cl})$ & $29.0(29.0-29.1)$ & $28.9(28.8-29.1)$ & $t=0.87 ; P=0.3793 ; d=0.06$ \\
\hline Cognitive impairment, \% $(n)^{\mathrm{e}}$ & $1(32 / 2407)$ & $1(3 / 209)$ & $\chi^{2}=0.02 ; P=0.898$ \\
\hline \multicolumn{4}{|l|}{ Orthostatic hypotension, \% $(n)^{f}$} \\
\hline $30 \mathrm{~s}$ & $14(327 / 2407)$ & $12(26 / 209)$ & $\chi^{2}=0.22 ; P=0.642$ \\
\hline 30 and $60 \mathrm{~s}$ & $7(163 / 2407)$ & $5(10 / 209)$ & $\chi^{2}=1.23 ; P=0.267$ \\
\hline 30,60 and $90 \mathrm{~s}$ & $4(100 / 2407)$ & $3(7 / 209)$ & $\chi^{2}=0.32 ; P=0.573$ \\
\hline Antidepressant use, \% (n) & $5(117 / 2407)$ & $21(43 / 209)$ & $\chi^{2}=82.69 ; P<0.001$ \\
\hline Antihypertensive use, $\%(n)^{h}$ & $37(883 / 2407)$ & $39(81 / 209)$ & $\chi^{2}=0.35 ; P=0.552$ \\
\hline \multicolumn{4}{|c|}{$\begin{array}{l}\text { Categorical variables were compared by chi-squared test. Normally distributed continuous variables were analysed by Student } t \text {-test. } d \text { denotes Cohen's } d \text {-test for effect size. Cl, confidence } \\
\text { interval; MMSE, Mini-Mental State Examination. } \\
\text { a. Blood pressure measured in seated position with a OMRON digital automatic blood pressure monitor. } \\
\text { b. Cardiac disease defined as self-report of heart attack, heart failure or angina. } \\
\text { c. Number of chronic diseases from the following list: liver disease, kidney disease, lung disease, cancer, arthritis and diabetes. } \\
\text { d. Stroke defined as self-report of prior stroke. } \\
\text { e. Cognitive impairment defined as Mini-Mental State Examination Score } \leq 24 \text {. } \\
\text { f. Orthostatic hypotension defined as drop in systolic blood pressure } \geq 20 \mathrm{~mm} \mathrm{Hg} \text { or drop in diastolic blood pressure } \geq 10 \mathrm{~mm} \mathrm{Hg} \text { at } 30 \mathrm{~s}, 30 \text { and } 60 \mathrm{~s} \text {, and } 30,60 \text { and } 90 \mathrm{~s} \text {, respectively, } \\
\text { compared with baseline blood pressure. } \\
\text { g. Antidepressants are those with Anatomical Therapeutic Classification codes N06AB, N06AX16, N06AX21, N06AX11, N06AX22 and N06AX12. } \\
\text { h. Antihypertensives are those with Anatomical Therapeutic Classification codes C02, C03, C07, C08 and C09. }\end{array}$} \\
\hline
\end{tabular}

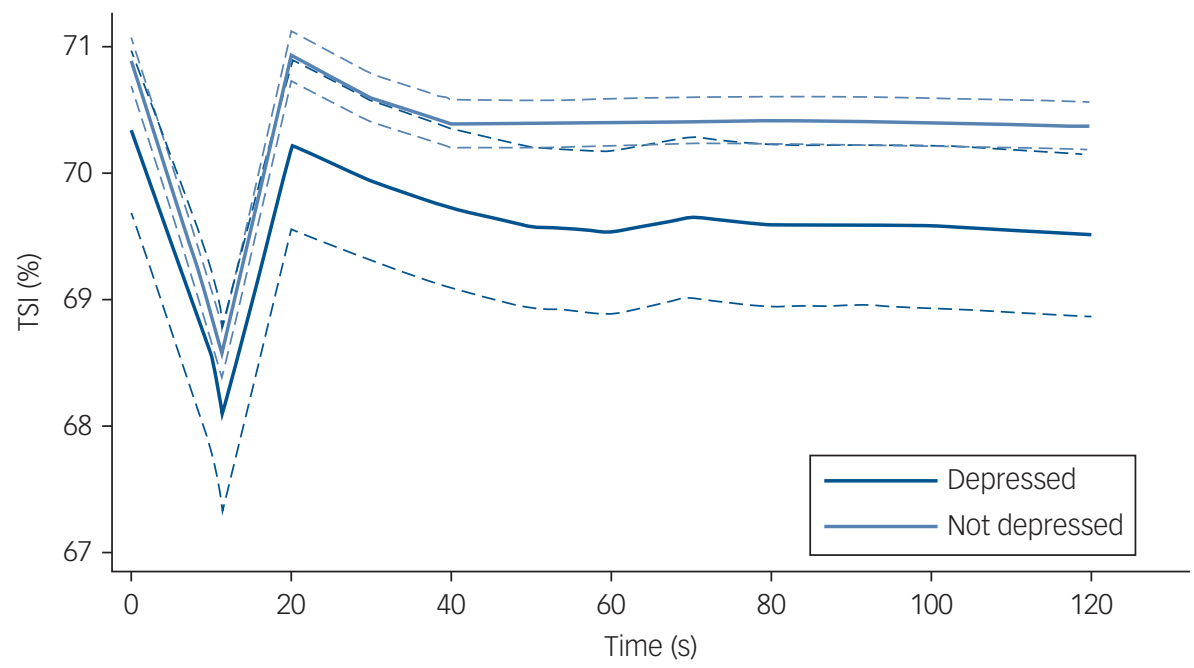

Fig. 1 Tissue saturation index (TSI) post-standing stratified by depression status. $N=2616$ (depressed $n=209$; non-depressed $n=2407$ ). TSI was measured by near-infrared spectroscopy. Solid lines indicate mean TSI and dashed lines indicate $95 \%$ confidence interval, for a given time point post-standing. TSI at 0 s equates to baseline TSI, i.e. the average of the readings between $30-60 \mathrm{~s}$ before standing. Depression status was based on the eight-item Centre for Epidemiological Studies Depression Scale. 


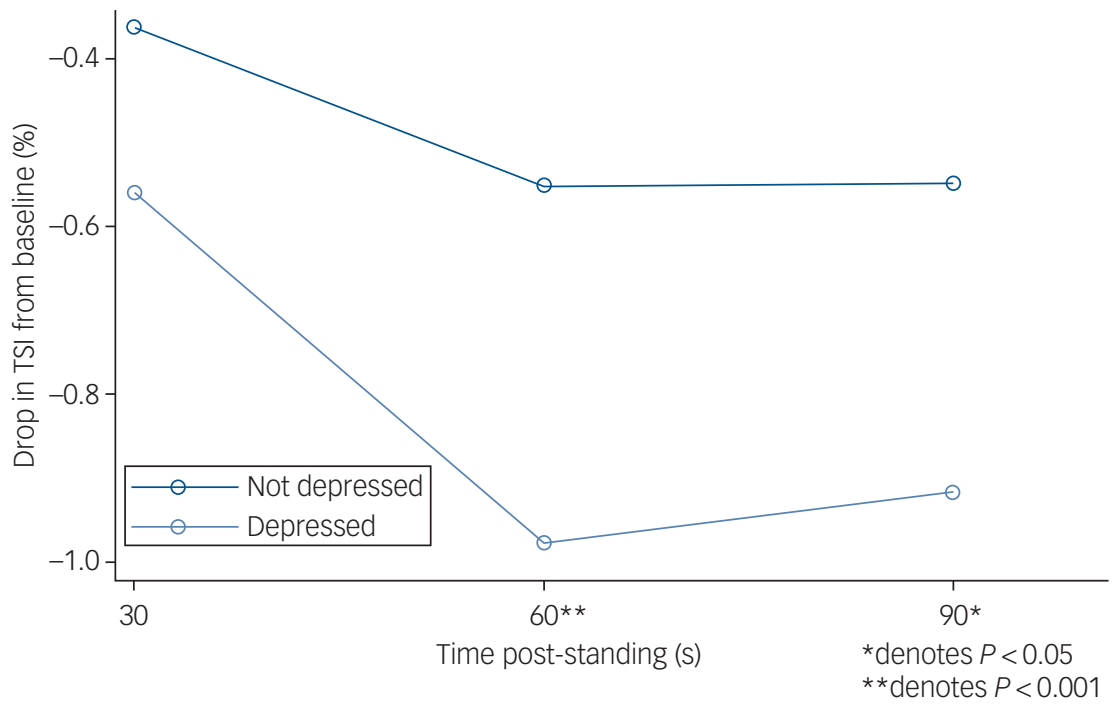

Fig. 2 Drop in tissue saturation index (TSI) from baseline after standing, by depression status. $N=2616$ (depressed $n=209$; non-depressed $n=2407$ ). TSI was measured by near-infrared spectroscopy at baseline (lying down, denoted as $0 \mathrm{~s}$, an average of the readings between 30-60 $\mathrm{s}$ before standing) and 30, 60 and $90 \mathrm{~s}$ post-standing. Results from multilevel modelling with TSI as the dependent variable nested within participant.

\section{Table 2 Multilevel linear regression models with tissue saturation index as dependent variable}

\begin{tabular}{|c|c|c|c|c|}
\hline TSI & Coefficient $(95 \% \mathrm{Cl})$ & s.e. & $z$ & $P$ \\
\hline \multicolumn{5}{|l|}{ Model 1} \\
\hline \multicolumn{5}{|l|}{ Depressive symptoms $\times$ time ${ }^{a}$} \\
\hline $30 s$ & $-0.20(-0.40$ to 0.01$)$ & 0.10 & -1.89 & 0.058 \\
\hline $60 \mathrm{~s}$ & $-0.43(-0.63$ to -0.22$)$ & 0.10 & -4.11 & $<0.001$ \\
\hline $90 \mathrm{~s}$ & $-0.37(-0.57$ to -0.16$)$ & 0.10 & -3.54 & $<0.001$ \\
\hline \multicolumn{5}{|l|}{ Model 2} \\
\hline \multicolumn{5}{|l|}{ Depressive symptoms $\times$ time $^{a}$} \\
\hline $30 \mathrm{~s}$ & $-0.21(-0.42$ to -0.01$)$ & 0.11 & -2.01 & 0.044 \\
\hline $60 \mathrm{~s}$ & $-0.46(-0.66$ to -0.25$)$ & 0.11 & -4.33 & $<0.001$ \\
\hline $90 \mathrm{~s}$ & $-0.39(-0.60$ to -0.19$)$ & 0.11 & -3.75 & $<0.001$ \\
\hline \multicolumn{5}{|l|}{ Random-effects parameters } \\
\hline & Estimate $(95 \% \mathrm{Cl})$ & s.e. & & \\
\hline Variance of constant & $21.6(20.4-22.8)$ & 0.61 & & \\
\hline Variance of residual & $1.04(1.00-1.07)$ & 0.02 & & \\
\hline \multicolumn{5}{|l|}{ Model 3: orthostatic hypotension added to model 2} \\
\hline \multicolumn{5}{|l|}{ Depressive symptoms $\times$ time $\times \mathrm{OH}^{\mathrm{b}}$} \\
\hline $30 \mathrm{~s}$ & $0.28(-0.35$ to 0.90$)$ & 0.32 & 0.88 & 0.381 \\
\hline $60 \mathrm{~s}$ & $-0.00(-0.62$ to 0.62$)$ & 0.32 & -0.00 & 0.998 \\
\hline $90 \mathrm{~s}$ & $-0.04(-0.67$ to 0.58$)$ & 0.32 & -0.14 & 0.889 \\
\hline \multicolumn{5}{|l|}{ Model 4: systolic blood pressure added to model 2} \\
\hline \multicolumn{5}{|c|}{ Depressive symptoms $\times$ time $\times$ systolic blood pressure ${ }^{c}$} \\
\hline $30 \mathrm{~s}$, systolic blood pressure <120 mm Hg & $-0.68(-1.17$ to -0.18$)$ & 0.25 & -2.67 & 0.008 \\
\hline 30 s, systolic blood pressure 140-159 mm Hg & $-0.30(-0.83$ to 0.24$)$ & 0.27 & -1.09 & 0.276 \\
\hline $30 \mathrm{~s}$, systolic blood pressure $\geq 160 \mathrm{~mm} \mathrm{Hg}$ & $-1.18(-2.05$ to -0.31$)$ & 0.44 & -2.66 & 0.008 \\
\hline 60 s, systolic blood pressure <120 mm Hg & $-0.53(-1.03$ to -0.03$)$ & 0.25 & -2.09 & 0.036 \\
\hline 60 s, systolic blood pressure $140-159$ mm Hg & $-0.09(-0.62$ to 0.45$)$ & 0.27 & -0.31 & 0.754 \\
\hline $60 \mathrm{~s}$, systolic blood pressure $\geq 160 \mathrm{~mm} \mathrm{Hg}$ & $-0.76(-1.62$ to 0.11$)$ & 0.44 & -1.70 & 0.088 \\
\hline 90 s, systolic blood pressure <120 mm Hg & $-0.54(-1.03$ to -0.04$)$ & 0.25 & -2.13 & 0.033 \\
\hline 90 s, systolic blood pressure 140-159 mm Hg & $-0.12(-0.65$ to 0.42$)$ & 0.27 & -0.42 & 0.671 \\
\hline 90 s, systolic blood pressure $\geq 160$ mm Hg & $-0.45(-1.32$ to 0.41$)$ & 0.44 & -1.03 & 0.305 \\
\hline \multicolumn{5}{|l|}{$\begin{array}{l}\text { Model 5: model } 2 \text { with antidepressant users excluded } \\
\text { Depressive symptoms } \times \text { time }^{d}\end{array}$} \\
\hline $30 \mathrm{~s}$ & $-0.24(-0.47$ to -0.01$)$ & 0.12 & -2.04 & 0.041 \\
\hline $60 \mathrm{~s}$ & $-0.45(-0.68$ to -0.22$)$ & 0.12 & -3.88 & $<0.001$ \\
\hline $90 \mathrm{~s}$ & $-0.40(-0.63$ to -0.17$)$ & 0.12 & -3.42 & 0.001 \\
\hline \multicolumn{5}{|c|}{$\begin{array}{l}N=2616 \text {. Results from multilevel modelling with TSI as the dependent variable. Model } 1 \text { is unadjusted; model } 2 \text { controls for age, gender, height, weight, number of chronic diseases, cognitive } \\
\text { impairment, cardiovascular disease, stroke and antidepressant and antihypertensive use. Orthostatic hypotension defined as drop in systolic blood pressure } \geq 20 \text { mm } \mathrm{Hg} \text { or drop in diastolic } \\
\text { blood pressure } \geq 10 \mathrm{~mm} \mathrm{Hg} \text { at either } 30,60 \text { or } 90 \mathrm{~s} \text { post-stand, compared with baseline blood pressure; systolic blood pressure measured twice in seated position with an OMRON digital cuff, } \\
\text { with the average of values then taken. Reference value is systolic blood pressure } 120-139 \mathrm{~mm} \mathrm{Hg} \text {. Cl, confidence interval; OH, orthostatic hypotension; TSI, tissue saturation index. } \\
\text { a. Depressive symptoms } \times \text { time denotes the two-way interaction between depressive symptoms and time after standing, allowing us to account for the fact that TSI at } 60 \mathrm{~s} \text { after standing is } \\
\text { significantly influenced by TSI at } 30 \mathrm{~s} \text { and so on. } \\
\text { b. Depressive symptoms } \times \text { time } \times \mathrm{OH} \text { denotes the three-way interaction between depressive symptoms, time after standing and OH and shows that the effect of the two-way interaction } \\
\text { between depressive symptoms and time on TSI is not modified by the presence or absence of OH. } \\
\text { c. Depressive symptoms } \times \text { time } \times \text { systolic blood pressure denotes the three-way interaction between depressive symptoms, time and systolic blood pressure and demonstrates that the } \\
\text { effect of the two-way interaction between depression and time on TSI is significantly affected by systolic blood pressure, i.e. it is only persistently significant (at } 30,60 \text { and } 90 \text { s) in those with } \\
\text { systolic blood pressure }<120 \mathrm{~mm} \mathrm{Hg} \text {. } \\
\text { d. Depressive symptoms } \times \text { time demonstrates that results are not significantly changed when antidepressant users are excluded from analyses. }\end{array}$} \\
\hline
\end{tabular}


As presented in Table 2, the time $\times$ group interactions revealed significantly lower TSI in participants with depressive symptoms compared with the non-depressed group at both 60 and 90 s post-stand, with coefficients of -0.43 ( $95 \%$ CI -0.63 to $-0.22, z=-4.11, P<0.001)$ and 0.37 (95\% CI -0.57 to -0.16 , $z=-3.54, P<0.001)$, respectively. Controlling for age, gender and clinical covariates such as cardiac disease, stroke and antidepressant use did not significantly attenuate these associations. Depressive symptoms were not associated with TSI at $30 \mathrm{~s}$ post-stand in unadjusted models. Full outputs from regression models are shown in supplementary material available at https://doi.org/10. 1192/bjp.2018.288.

The depressive symptoms $\times$ time interaction was not modified by $\mathrm{OH}$, suggesting that coexisting $\mathrm{OH}$ does not influence the relationship between depressive symptoms and TSI across these time points (see Table 2, model 3).

However, after addition of systolic blood pressure to model 5, depressive symptoms $\times$ time interaction was no longer significant, suggesting that systolic blood pressure may modify the association between depressive symptoms and frontal lobe perfusion. At 30, 60 and $90 \mathrm{~s}$ post-stand, there is a significant drop in TSI in those who had depressive symptoms with systolic blood pressure $<120 \mathrm{~mm} \mathrm{Hg}$, compared with non-depressed participants with normal blood pressure. This is also the case for those who have depressive symptoms with high systolic blood pressure values $(\geq 160 \mathrm{~mm} \mathrm{Hg})$ at $30 \mathrm{~s}$ (see Table 2, model 4).

Table 2 also demonstrates that findings remained robust after rerunning analyses with exclusion of all participants taking antidepressant medication.

\section{Discussion}

This study shows that, in a cohort of community-dwelling older people, participants with depressive symptoms had lower frontal lobe perfusion measured by NIRS after standing, and that depressive symptoms were associated with a more significant drop in frontal lobe perfusion at both 30, 60 and $90 \mathrm{~s}$, when controlling for important covariates including prior stroke, heart disease and cognitive impairment.

Further analyses found that this association was not modified significantly by orthostatic hypotension and was also independent of antidepressant use. However, addition of systolic blood pressure to the analysis demonstrated that the association between depressive symptoms and TSI was only persistent across time points in those with systolic blood pressure $<120 \mathrm{~mm} \mathrm{Hg}$, suggesting that lower systolic blood pressure in depressed individuals may be the predominant driver of this association.

Although the degree of drop in TSI we demonstrate in this study is relatively small $(0.5-1 \%)$, it is likely to be significant, given that prior work has shown that patients with spontaneous vasovagal syncope undergoing tilt table testing had a change in TSI of $4.5 \%$ $( \pm 3.0 \%),{ }^{27}$ and that the changes observed in this study are provoked only by changing from a supine to standing position, which is likely to occur multiple times per day/week.

These findings are supported by prior neuroimaging studies showing a similar association between late-life depression and both global and frontal cerebral perfusion. ${ }^{11,12}$ Smaller studies utilising NIRS have also demonstrated similar disparities between depressed and non-depressed participants when undertaking cognitive tasks. ${ }^{28,29}$ However, our findings are cross-sectional and the direction of the relationship between frontal lobe cerebral perfusion and depressive symptoms remains uncertain, with limited longitudinal analyses to date.
There is also some evidence that remission of depression leads to subsequent improvements in cerebral blood flow in specific brain regions, including the frontal lobe, suggesting that frontal lobe perfusion deficits may form part of the clinical syndrome of depression in later life. Rather than representing a factor in the aetiology of depression, it may be that these deficits are related to reduced demand in the context of frontal hypoactivity, and that they may respond to appropriate therapy, such as antidepressants or electroconvulsive therapy. ${ }^{30,31}$ Furthermore, the disparity in frontal lobe perfusion between depressed and non-depressed participants that we have demonstrated is significant only when standing, and not at rest. This may be related to the fact that when we stand, blood pressure and therefore cerebral perfusion generally drop, and although baroreflexes act to return these to baseline, blood flow is preferentially directed toward the most metabolically active brain regions and given the reduced frontal lobe activity seen in depression, blood flow may be compromised there temporarily.

Conversely, there is also some evidence that cerebral perfusion deficits may have a role in the aetiology of depression in later life. WMHs have been implicated in late-life depression and it has been shown that these lesions can be caused by strategic deficits in cerebral perfusion. ${ }^{32}$ Depression has been identified as a potential prodromal feature of dementia and pathological changes in brain perfusion have also been identified during this prodrome. Depression in later life has also been also been independently associated with other conditions where global cerebral hypoperfusion occurs, including unexplained falls and syncope. ${ }^{33}$ Additionally, conditions causing global cerebral hypoperfusion, such as orthostatic hypotension or chronically low blood pressure, have been shown to increase the risk of incident depression in older people. $^{11,12}$

Understanding the nature of the link between incident depression and cerebral perfusion is important because cerebral blood flow is potentially modifiable. Factors such as alcohol intake, blood pressure and cognitive training may influence cerebral blood flow. ${ }^{34}$ Exercise has also been shown to enhance cerebral blood flow in older people, as well as improving remission rates in late-life depression when added to standard therapy. ${ }^{35}$ Other factors we have shown in this study that are independently associated with frontal lobe perfusion include heart disease and higher weight. Lower blood pressure, as well as $\mathrm{OH}$, is significantly associated with lower frontal lobe TSI, whereas higher values of systolic blood pressure are also associated with higher TSI values at $90 \mathrm{~s}$ after standing.

There are some limitations of this study that should be noted. Depressive symptoms were assessed with the CES-D-8 rather than the gold-standard structured psychiatric interview. However, the eight-item CES-D has been well validated in the TILDA population. ${ }^{25,26}$ Furthermore, data is cross-sectional with no prospective follow-up to determine a longitudinal relationship between cerebral perfusion and depressive symptoms. Information regarding chronic illnesses, such as diabetes or stroke, are based on self-report and may therefore be subject to self-report bias and under-reporting. Importantly, although we consider that cerebral hypoperfusion may cause frontal white matter disease, we do not have access to structural neuroimaging, such as MRI, which would help confirm this association. However, prior studies have demonstrated a significant association between cerebral perfusion and WMH burden. ${ }^{32}$

The strengths of this study include the well-described large population-based cohort of older people involved. This is the largest study to date examining the association between NIRS and depressive symptoms in older people and controls for important covariates such as cardiovascular disease and antidepressant use, 
which has not been a feature of studies, including those using neuroimaging techniques, up to now. This study also shows that it is feasible for a large population of older people to undergo bedside testing with NIRS for cerebral perfusion analysis. NIRS is non-invasive, portable and given the results we have demonstrated, could therefore potentially be used as a biomarker of either risk or response to treatment in late-life depression.

In conclusion, we have demonstrated that lower frontal lobe perfusion, related to lower baseline systolic blood pressure, is associated with clinically significant depressive symptoms in a cohort of community-dwelling older people. Given the recognised longitudinal association between lower blood pressure and depression in older people, this may represent a potential therapeutic target for prevention of incident depression.

Robert Briggs, MD, Research Fellow, The Irish Longitudinal Study on Ageing, Trinity College Dublin; Mercer's Institute for Successful Ageing, St James's Hospital; and Agerelated Health Care, Tallaght Hospital, Ireland; Daniel Carey, PhD, Biostatistician, The Irish Longitudine Study on Ageng, Trinity College Dublin, reland; Registra in Registrar in Geriatric Medicine, Mercer's Institute for Successful Ageing, St James's
Hospital, Ireland; Triona McNicholas, MD, Research Fellow, The Irish Longitudinal Study on Ageing, Trinity College Dublin; and Mercer's Institute for Successful Ageing, St James's Hospital, Ireland; Louise Newman, PhD, Bioengineer, The Irish Longitudinal Study on Ageing, Trinity College Dublin, Ireland; Hugh Nolan, PhD, Bioengineer, The Irish Longitudinal Study on Ageing, Trinity College Dublin, Ireland; Sean P. Kennelly, PhD, Consultant Geriatrician, Age-related Health Care, Tallaght Hospital, Ireland; Rose Anne Kenny, MD, Consultant Geriatrician, The Irish Longitudinal Study on Ageing, Trinity College Dublin; and Mercer's Institute for Successful Ageing, St James's Hospital, Ireland

Correspondence: Robert Briggs, The Irish Longitudinal Study on Ageing (TILDA), Mercer's Institute for Successful Ageing, St James's Hospital, James's Street, Dublin 8, Ireland. Email: briggsr@tcd.ie

First received 8 Jun 2018, final revision 19 Oct 2018, accepted 9 Nov 2018

\section{Supplementary material}

Supplementary material is available online at https://doi.org/10.1192/bjp.2018.288.

\section{Funding}

Financial support was provided by Irish Government, the Atlantic Philanthropies and Irish Life plc. These funders had no involvement in the study design, collection, analysis and interpretation of data, writing of the paper or submission for publication. Any views expressed in this report are not necessarily those of the Department of Health and Children or of the Minister for Health.

\section{References}

1 Taylor WD, Aizenstein HJ, Alexopoulos GS. The vascular depression hypothesis: mechanisms linking vascular disease with depression. Mol Psychiatry 2013; 18 (9): 963-74.

2 Alexopoulos GS. Frontostriatal and limbic dysfunction in late-life depression. Am J Geriatr Psychiatry 2002; 10(6): 687-95.

3 Almeida OP, Burton EJ, Ferrier N, McKeith IG, O'Brien JT. Depression with late onset is associated with right frontal lobe atrophy. Psychol Med 2003; 33(4): 675-81.

4 Dotson VM, Davatzikos C, Kraut MA, Resnick SM. Depressive symptoms and brain volumes in older adults: a longitudinal magnetic resonance imaging study. J Psychiatry Neurosci 2009; 34(5): 367-75.

5 MacFall JR, Payne ME, Provenzale JE, Krishnan KR. Medial orbital frontal lesions in late-onset depression. Biol Psychiatry 2001; 49(9): 803-6.

6 Herrmann LL, Le Masurier M, Ebmeier KP. White matter hyperintensities in late life depression: a systematic review. J Neurol Neurosurg Psychiatry 2008; 79(6): 619-24.

7 Nobuhara K, Okugawa G, Sugimoto T, Minami T, Tamagaki C, Takase K, et al. Frontal white matter anisotropy and symptom severity of late-life depression: a magnetic resonance diffusion tensor imaging study. J Neurol Neurosurg Psychiatry 2006; 77(1): 120-2.

8 Kumar A, Thomas A, Lavretsky H, Yue K, Huda A, Curran J, et al. Frontal white matter biochemical abnormalities in late-life major depression detected with proton magnetic resonance spectroscopy. Am J Psychiatry 2002; 159(4): 630-6.
9 Lai T, Payne ME, Byrum CE, Steffens DC, Krishnan KR. Reduction of orbital frontal cortex volume in geriatric depression. Biol Psychiatry 2000; 48(10): $971-5$

10 Hoffmann M. The human frontal lobes and frontal network systems: an evolutionary, clinical, and treatment perspective. ISRN Neurol 2013; 2013: 892459.

11 Briggs R, Kenny RA, Kennelly SP. Does baseline hypotension predict incident depression in a cohort of community-dwelling older people? Data from The Irish Longitudinal Study on Ageing (TILDA). Age Ageing 2017; 46(4): 648-53.

12 Briggs R, Carey D, Kennelly SP, Kenny RA. Longitudinal association between orthostatic hypotension at 30 seconds post standing and late life depression. Hypertension 2018; 71(5): 946-54.

13 Navarro V, Gastó C, Lomeña F, Mateos JJ, Marcos T. Frontal cerebral perfusion dysfunction in elderly late-onset major depression assessed by 99MTC-HMPAO SPECT. Neurolmage 2001; 14(1 Pt 1): 202-5.

14 Lesser IM, Mena I, Boone KB, Miller BL, Mehringer CM, Wohl M. Reduction of cerebral blood flow in older depressed patients. Arch Gen Psychiatry 1994; 51 (9): 677-86.

15 Alosco ML, Spitznagel MBB, Cohen R, Raz N, Sweet LH, Josephson R, et al. Reduced cerebral perfusion predicts greater depressive symptoms and cog nitive dysfunction at a 1-year follow-up in patients with heart failure. Int J Geriatr Psychiatry 2014; 29(4): 428-36.

16 Strangman G, Boas DA, Sutton JP. Non-invasive neuroimaging using nearinfrared light. Biol Psychiatry 2002; 52(7): 679-93.

17 Taussky P, O'Neal B, Daugherty WP, Luke S, Thorpe D, Pooley RA, et al. Validation of frontal near-infrared spectroscopy as noninvasive bedside monitoring for regional cerebral blood flow in brain-injured patients. Neurosurg Focus 2012; 32(2): E2.

18 Whelan BJ, Savva GM. Design and methodology of the Irish Longitudinal Study on Ageing. J Am Geriatr Soc 2013; 61(Suppl 2): S265-8.

19 Nieuwhof F, Reelick MF, Maidan I, Mirelman A, Hausdorff JM, Olde Rikkert MGM, et al. Measuring prefrontal cortical activity during dual task walking in patients with Parkinson's disease: feasibility of using a new portable fNIRS device. Pilot Feasibility Stud 2016; 2: 59.

20 Bale G, Elwell CE, Tachtsidis I. From Jöbsis to the present day: a review of clinical near-infrared spectroscopy measurements of cerebral cytochrome-coxidase. J Biomed Opt 2016; 21(9): 091307.

21 Colier WN, Binkhorst RA, Hopman MT, Oeseburg B. Cerebral and circulatory haemodynamics before vasovagal syncope induced by orthostatic stress. Clin Physiol 1997; 17(1): 83-94.

22 Jones S, Chiesa ST, Chaturvedi N, Hughes AD. Recent developments in nearinfrared spectroscopy (NIRS) for the assessment of local skeletal muscle microvascular function and capacity to utilise oxygen. Artery Res 2016; 16: 25-33.

23 Finucane C, O'Connell MD, Fan CWW, Savva GM, Soraghan CJ, Nolan $\mathrm{H}$, et al. Age-related normative changes in phasic orthostatic blood pressure in a large population study: findings from The Irish Longitudinal Study on Ageing (TILDA). Circulation 2014; 130(20): 1780-9.

24 Freeman R, Wieling W, Axelrod FB, Benditt DG, Benarroch E, Biaggioni I, et al. Consensus statement on the definition of orthostatic hypotension, neurally mediated syncope and the postural tachycardia syndrome. Clin Auton Res 2011; 21(2): 69-72

25 Briggs R, Carey D, O'Halloran A, Kenny RA, Kennelly SP. Validation of the 8-item Centre for Epidemiological Studies Depression Scale in a cohort of communitydwelling older people: data from The Irish Longitudinal Study on Ageing (TILDA). Eur Geriatr Med 2018; 9: 121-126.

26 O'Halloran AM K, King-Kallimanis BL RA. The latent factors of depression from the short forms of the CES-D are consistent, reliable and valid in communityliving older adults. Eur Geriatr Med 2014; 5(2): 97-102.

27 Bachus E, Holm H, Hamrefors V, Melander O, Sutton R, Magnusson M, et al. Monitoring of cerebral oximetry during head-up tilt test in adults with history of syncope and orthostatic intolerance. Europace 2018; 20(9): 1535-42.

28 Rosenbaum D, Hagen K, Deppermann S, Kroczek AM, Haeussinger FB, Heinzel S, et al. State-dependent altered connectivity in late-life depression: a functional near-infrared spectroscopy study. Neurobiolf Aging 2016; 39 $57-68$

29 Ma X-Y, Wang Y-J, Xu B, Feng K, Sun GX, Zhang XQ, et al. Near-infrared spectroscopy reveals abnormal hemodynamics in the left dorsolateral prefrontal cortex of menopausal depression patients. Dis Markers 2017: 2017: 1695930.

30 Abi Zeid Daou M, Boyd BD, Donahue MJ, Albert K, Taylor WD. Frontocingulate cerebral blood flow and cerebrovascular reactivity associated with antidepressant response in late-life depression. J Affect Disord 2017; 215: 103-10.

31 Navarro V, Gastó C, Lomeña F, Torres X, Mateos JJ, Portella MJ, et al. Prognostic value of frontal functional neuroimaging in late-onset severe major depression. Br J Psychiatry 2004; 184(4): 306-11. 
32 Brickman AM, Zahra A, Muraskin J, Steffener J, Holland CM, Habeck C, et al. Reduction in cerebral blood flow in areas appearing as white matter hyperintensities on magnetic resonance imaging. Psychiatry Res 2009; 172(2): 117-20.

33 Briggs R, Kennelly SP, Kenny RAA. Does baseline depression increase the risk of unexplained and accidental falls in a cohort of community-dwelling older people? Data from The Irish Longitudinal Study on Ageing (TILDA). Int J Geriatr Psychiatry 2018; 33(2): e205-11.

34 Mozolic JL, Hayasaka S, Laurienti PJ. A cognitive training intervention increases resting cerebral blood flow in healthy older adults. Front Hum Neurosci 2010; 4: 16
35 Penninx BW, Rejeski WJ, Pandya J, Miller ME, Di Bari M, Applegate WB, et al. Exercise and depressive symptoms: a comparison of aerobic and resistance exercise effects on emotional and physical function in older persons with high and low depressive symptomatology. J Gerontol B Psychol Sci Soc Sci 2002; 57 (2): P124-32.

\section{psychiatry in literature}

\section{Dostoyevsky's Brothers Karamazov as essential psychiatric text}

\section{Jeremy Holmes}

Dostoyevsky's The Brothers Karamazov is generally considered one of the greatest works of the 19th Century. It was Freud's favourite novel, embodying his contention that parricide is a universal human - or at least male wish, and that its associated guilt lies at the root of the religious impulse. For bipolar Virginia Woolf, Dostoyevsky 'alone among writers has the power of reconstructing those most swift and complicated states of mind'.

Despite its iconic status, Brothers Karamazov is a complex assembly of styles, stories and genres - whodunnit, the science-versus-religion debate, epilepsy symptomatology, chauvinistic celebration of the Russian spirit, courtroom drama and forensic psychiatry dilemma. The story centres around four brothers and the murder of their 'sensualist', neglectful and much-married father, Fyodor. Each brother embodies states of mind with which psychiatrists need to be familiar. Despite the prosecutor's dismissal of an insanity (or 'aberration') defence, Dmitri surely suffers from a mood disorder. He is subject to bouts of manic activity, is often violent, hypersexual, profligately spends money (his own and other peoples'), constantly changes his mind and, unable to differentiate wish from action, confesses to a crime he hasn't committed.

His half-brother Ivan, ultra-rationalist, existentialist prototype (much admired by Camus and Sartre) annunciates the book's principal themes: (a) without God, 'are all things possible?' and (b) 'everyone wishes their father dead'. Ivan is the intertextual 'author' of the famous Grand Inquisitor section in which the worldly torturer explains that a contemporary Christ would have to be liquidated. Ivan is mostly cut off from his feelings but, delirious from infection, he hallucinates a Devil-Avatar with whom he has a prolonged and profound dialogue about the nature and necessity of evil.

The third son, Smerkyadov, Fyodor's 'natural' child, is, as we would now say, 'on the spectrum': clever and calculating, interpersonally challenged and (spoiler coming) self-confessedly the murderer.

The fourth son and the book's hero is the saint-like proto-therapist Alyosha. Alyosha's honesty, composure and empathy are examples to all in the helping professions. His guru is Father Zosima, an all-accepting, all-forgiving libertarian monk, whose humanity and cheerfulness counterbalance the novel's unremitting dark themes.

There is also a host of vivid minor characters. Kolya, the precocious adolescent, all brilliance and self-doubt; Lisa, the self-harming teenage girl in love with Alyosha: Ratikin the scheming proto-Marxist intellectual, a step away from the oncoming Russian terrorism; a pompous Moscow doctor, all self-importance, avarice and denigration of local services; eloquent lawyers for the prosecution and defence.

Brothers Karamazov was written in the aftermath of Dostoyevsky's 3-year-old son's death from epilepsy. The book is suffused with a sense of loss and grief. Its exploration of father-son relationships - Alyosha and Zosima, Fyodor and his sons, the Pope and his flock, God himself - speaks to our contemporary problematic masculinities. (By contrast, Dostoyevsky is notoriously weak at depicting women: Brothers Karamazov's main female characters are little more than caricatures: Katarina, hell-hath-no-fury rejected lover and tart-with-a-heart Grushenka.)

The book concludes with the poignant funeral of Kola's playmate, Ilusha. Alyosha, father-like, enjoins the boy's assembled school friends to transcend their loss: '... some good sacred memory preserved from childhood is the best education. If a man carries many such memories with him into life, he is safe to the end of his days, and if one has only one good memory left in one's heart, even that may sometime be the means of saving us'. Innocence, love, reciprocity, relationship: Brothers Karamazov offers lessons in true resilience which our target-obsessed, ahistorical culture - psychiatry not excepted - needs urgently to relearn.

Copyright (c) The Royal College of Psychiatrists 2019 